\title{
Performance Evolution of Niobium Doped Lanthanum Strontium Ferrate Perovskite Anode for Solid Oxide Fuel Cells
}

\author{
J. Lia ${ }^{\mathrm{a}, \mathrm{b}}$, Z. Lü̈ ${ }^{\mathrm{b}}$ J. T. S. Irvine ${ }^{\mathrm{a}}$ \\ ${ }^{a}$ School of Chemistry, University of St Andrews, St Andrews KY16 9ST, UK \\ ${ }^{b}$ Department of Physics, Harbin Institute of Technology, Harbin 150001, China
}

In this paper, evolutions of $\mathrm{La} 0.8 \mathrm{Sr}_{0.2} \mathrm{Fe}_{0.9} \mathrm{Nb}_{0.1} \mathrm{O}_{3-\delta}(\mathrm{LSFNb})$ anodes for solid oxide fuel cells (SOFCs) with different microstructures are investigated, which are prepared by adjusting the weight ratio of electrode powder/organic binder during the preparation of slurries. AC impedance spectra clearly reveals that LSFNb anode made from 7:4-slurry shows better microstructure and lower polarization resistance $\left(R_{P}\right)$ compared with those of LSFNb anode made from 7:2.5-slurry. Better electrochemical performance is obtained on the single cells using 7:4-anode and cathode slurries with maximum power density (MPD) reaching $331.9 \mathrm{~mW} \cdot \mathrm{cm}^{-2}$ after discharged for $200 \mathrm{~h}$ fueled by $\mathrm{H}_{2}$, compared with 285.8 $\mathrm{mW} \cdot \mathrm{cm}^{-2}$ of the cell made from 7:2.5-slurries. The two cells exhibit excellent stability with undetectable degenerations for over $200 \mathrm{~h}$. These results demonstrate that LSFNb made from thin slurries possesses better electrochemical performance and can active continuously without significant agglomeration, making porous LSFNb a promising perovskite anode candidate for SOFCs.

\section{Introduction}

Solid oxide fuel cell (SOFC) is an efficient, cost-effective and environmental friendly energy conversion device by electrochemical reactions with fuel-flexibility, which has attracted tremendous research attention in recent years (1-3). Superior catalytic activity and high durability in reducing environment are essential to anode materials as fuels are oxidized at the anode. The state-of-the-art Ni-YSZ cermet has been widely investigated as the anode of SOFCs owing to its excellent catalytic activity toward fuels. Nevertheless, Ni-YSZ is vulnerable to sulfur poisoning and carbon deposition as well as redox cycling, which significantly hinder its practical applications (4-6). Thus, it is useful and important to develop alternative anode materials for SOFCs.

Significant efforts have been devoted to developing novel anode materials and microstructures to overcome the drawbacks of Ni-YSZ cermet during the past few decades. Some perovskite oxides, with mixed ionic and electronic conductivity (MIEC), have been demonstrated as anode materials with improved redox stability, sulfur poisoning resistance and coking tolerance, examples include $\mathrm{La}_{0.75} \mathrm{Sr}_{0.25} \mathrm{Cr}_{0.5} \mathrm{Mn}_{0.5} \mathrm{O}_{3-\delta}$ (LSCM), $\mathrm{La}_{0.3} \mathrm{Sr}_{0.7} \mathrm{TiO}_{3-\delta}$ (LST) and $\mathrm{La}_{8} \mathrm{Sr}_{0.2} \mathrm{Sc}_{x} \mathrm{Mn}_{1-\mathrm{x}} \mathrm{O}_{3-\delta}$ (LSSM) (7-9). Nonetheless, electrical conductivity and catalytic activity of these perovskite oxides are far insufficient compared with Ni-YSZ cermet. Double perovskite oxides, including $\mathrm{Sr}_{2} \mathrm{MgMoO}_{6-\delta}$ (SMMO), $\mathrm{Sr}_{2} \mathrm{FeMoO}_{6-\delta}$ (SFMO) and $\mathrm{PrBaMn}_{2} \mathrm{O}_{5+\delta}$ deliver high electrochemical 
performance in $\mathrm{H}_{2}$ and hydrocarbon fuels with great stability, high electrical conductivity and anti-sulfur poisoning are also found on these anodes, shedding some light on the perovskite alternative anode for SOFCs (10-12).

Catalytic activity of perovskite oxides is mainly decided by B-site elements. Lanthanum ferrite-based perovskite oxides, including $\mathrm{La}_{0 .} \mathrm{Sr}_{0.2} \mathrm{FeO}_{3-\delta}$ (LSF) and $\mathrm{La}_{0.6} \mathrm{Sr}_{0.4} \mathrm{Co}_{0.2} \mathrm{Fe}_{0.8} \mathrm{O}_{3-\delta}$ (LSCF), are widely investigated as oxygen materials for SOFCs owing to their mixed ionic and electronic conductivity in air and excellent catalytic activity toward oxygen reduction reaction (ORR) $(13,14)$. However, operating in anodic reducing atmosphere would deduce the decomposition of Fe based perovskite oxides (15). It has been proved that the introduction of $\mathrm{Nb}$ on the $\mathrm{B}$-site is an effective way to promote structural stability of perovskite oxides in reducing atmosphere as the energy state of $\mathrm{Nb}^{5+}$ are located far above the Fermi level and robust $\mathrm{Nb}-\mathrm{O}$ bonds can stabilize the lattice (16). Some $\mathrm{Nb}$-doped materials, including $\mathrm{La}_{0.4} \mathrm{Sr}_{0.6} \mathrm{Co}_{0.2} \mathrm{Fe}_{0.7} \mathrm{Nb}_{0.1} \mathrm{O}_{3-\delta}$, $\mathrm{La} 0 .{ }_{9} \mathrm{Ca}_{0.1} \mathrm{Fe}_{0.9} \mathrm{Nb}_{0.1} \mathrm{O}_{3-\delta}$ and $\operatorname{Pr}_{0.8} \mathrm{Sr}_{1.2}(\mathrm{Co}, \mathrm{Fe})_{0.8} \mathrm{Nb}_{0.2} \mathrm{O}_{4}$ have been verified as high performance anodes with good performance stability (17-19).

In our previous study, we successfully synthesized and reported a novel $\mathrm{Nb}$ doped perovskite oxide, $\mathrm{La}_{0.8} \mathrm{Sr}_{0.2} \mathrm{Fe}_{0.9} \mathrm{Nb}_{0.1} \mathrm{O}_{3-\delta}$ (LSFNb), as a redox-stable and sulfur-tolerant anode for SOFC (20). Improved structural stability and competitive electrical conductivity in severe reducing atmosphere of LSFNb were also observed. However, low-frequency resistance $\left(R_{L}\right)$ of LSFNb anode significantly increased after discharging under constant current density of $275 \mathrm{~mA} \cdot \mathrm{cm}^{-2}$ for over $100 \mathrm{~h}$ at $800{ }^{\circ} \mathrm{C}$. The increment of $R_{L}$ mainly corresponds to coarsening and agglomeration of LSFNb anode particles, which would result in the difficulty of gas diffusion and adsorption process. In general, metal particles tend to agglomerate after long-term operation in metal-cermet anodes. While the agglomeration of perovskite electrodes could be alleviated by optimizing the microstructure and preparation procedures, such as enhancing electrode porosity, preparing perovskite oxide-electrolyte composite electrodes, using infiltrated electrodes and so on. In this paper, SOFCs with different microstructures were obtained by adjusting the weight ratio of electrode powder/organic binder when preparing electrode slurries. The electrochemical performance of LSFNb anode and whole cells made from different slurries was recorded after discharged for certain hours. The obtained results demonstrate that the electrochemical performance and microstructure of LSFNb anode could be promoted by reducing the weight ratio of electrode/organic binder. In addition, both low frequency resistance $\left(R_{L}\right)$ and high frequency resistance $\left(R_{H}\right)$ of optimized LSFNb anode generally keep activation during the constant discharging for over $200 \mathrm{~h}$, which correspond to the formation of more oxygen vacancies and in-situ growth of nano-sized $\mathrm{Fe}^{0}$ particles on the surface of LSFNb anode, making LSFNb a promising anode candidate with excellent catalytic activity for SOFCs.

\section{Experimental Section}

The $\mathrm{La}_{0.8} \mathrm{Sr}_{0.2} \mathrm{Fe}_{0.9} \mathrm{Nb}_{0.1} \mathrm{O}_{3-\delta}$ (LSFNb) catalyst was prepared via sol-gel method as we described previously (20). For preparing LSFNb anode and LSM/ScSZ cathode slurries, $\mathrm{LSFNb}$ anode powder and LSM/ScSZ powder were mixed with organic binder (ethyl cellulose and $\alpha$-terpilenol) at the weight ratio of 7:2.5 and 7:4, respectively. LSFNb slurry and LSM/ScSZ slurry with the same ratio were coated onto SDC buffer layer side and 
electrolyte side at an effective area of $0.11 \mathrm{~cm}^{2}$, respectively, followed by sintering at $1100{ }^{\circ} \mathrm{C}$ for $2 \mathrm{~h}$ in air.

Dry $\mathrm{H}_{2}$ at the flow rate of $50 \mathrm{ml} \cdot \mathrm{min}^{-1}$ controlled by mass flow controller (MFC) was fed to anode chamber, while the cathode was exposed to ambient air. Electrochemical measurements were conducted via an electrochemical workstation (Bio-logic, VSP). The output voltages of the two prepared cells were recorded under a constant current density of $300 \mathrm{~mA} \cdot \mathrm{cm}^{-2}$ at $800{ }^{\circ} \mathrm{C}$ for over $200 \mathrm{~h}$. Electrochemical impedance spectra were measured from $200 \mathrm{kHz}$ to $30 \mathrm{mHz}$ with an AC amplitude of $10 \mathrm{mV}$. Voltage-current density $(V-I)$ polarization curves and EIS were recorded after discharged for $1 \mathrm{~h}, 10 \mathrm{~h}, 50$ $\mathrm{h}, 100 \mathrm{~h}$ and $200 \mathrm{~h}$, respectively. The microstructures of anodes after operated for different hours were examined by a scanning electron microscope (SEM, Hitachi SU70). The morphology of reduced LSFNb powder was evaluated via a transmission electron microscope (TEM, JEL-2100F).

\section{Results and Discussion}

For simplicity, LSFNb anode made from slurries with the LSFNb/organic binder weight ratio of 7:2.5 and 7:4 are named as LSFNb anode- 1 and anode-2, respectively. AC impedance spectra of the two anodes were measured at $800{ }^{\circ} \mathrm{C}$ with the help of a silver reference electrode after discharging for certain hours under current density of $0.3 \mathrm{~A} \cdot \mathrm{cm}^{-2}$. The ohmic resistance were substrated for comparison clearly and the results are shown in Figure 1(a) and (b), respectively. Generally, high-frequency arc $\left(R_{H}\right)$ of AC impedance spectra is associated with redox reaction and charge transfer process, while lowfrequency arc $\left(R_{L}\right)$ is related to gas adsorption and dissociation, gas diffusion and mass transfer process $(21,22) . R_{H}$ of LSFNb anode-1 decreases with the operating time, indicative of the enhancement of charge transfer ability for LSFNb anode. Meanwhile, after discharging for $10 \mathrm{~h}$, the low frequency resistance $\left(R_{L}\right)$ of the LSFNb anode-1 increases slightly, but since then it decreases continuously till the total electrochemical measurement of $200 \mathrm{~h}$, from $1.12 \Omega \cdot \mathrm{cm}^{2}$ at $10 \mathrm{~h}$ to $0.83 \Omega \cdot \mathrm{cm}^{2}$ at $200 \mathrm{~h}$. The LSFNb anode-1 might suffer a slight agglomeration process during the first 10 -h operation and reach a relatively stable condition afterwards.
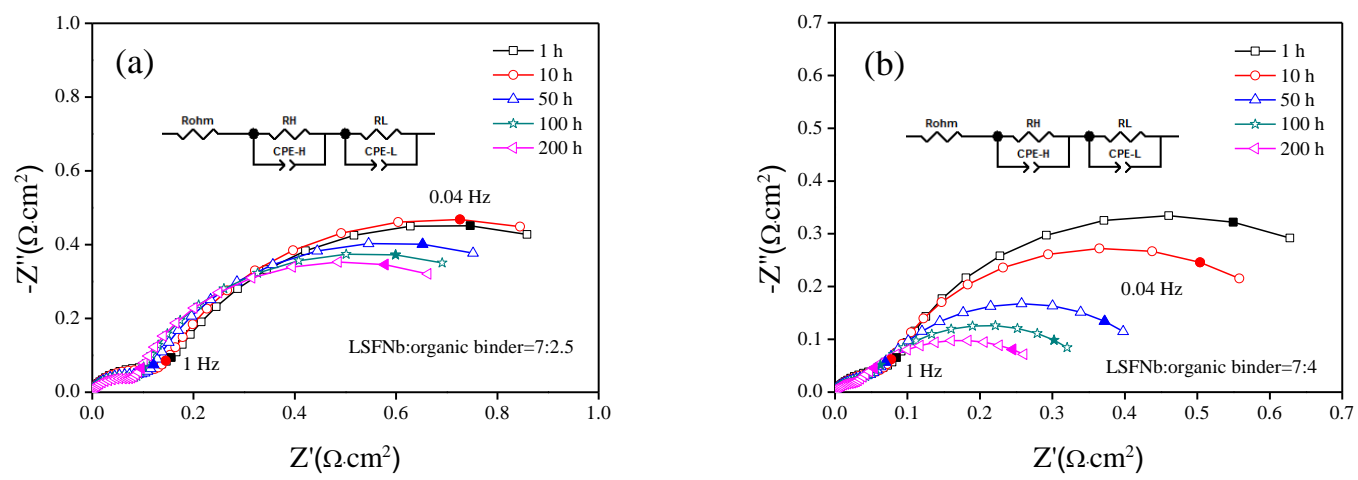

Figure 1. Time dependence of polarization resistance of LSFNb anode made from slurries with LSFNb/organic binder at the weight ratio of (a) 7:2.5, (b) 7:4.

However, $R_{L}$ of LSFNb anode made from 7:4-slurry (LSFNb anode-2) decreases continuously and significantly, from $0.74 \Omega \cdot \mathrm{cm}^{2}$ at $1 \mathrm{~h}$ to $0.29 \Omega \cdot \mathrm{cm}^{2}$ at $200 \mathrm{~h}$ while $R_{H}$ 
also decreases according to the fitting results. It is worthy noticing that $R_{L}$ and $R_{H}$ of LSFNb anode- 2 are significantly smaller than those of LSFNb anode- 1 at each testing time. In general, electrode slurry with more ratio of organic binder would deduce higher porosity of electrode after sintering, which could facilitate gas diffusion and adsorption process and alleviate agglomeration during operation. Higher porosity, specific surface area and more uniformly distributed LSFNb particles (shown in Figure 2) make LSFNb anode- 2 have much better electrochemical performance compared with LSFNb anode- 1 . In addition, the agglomeration of LSFNb anode particles during operation at high temperature could be alleviated by using thin slurry, as the low frequency resistance of LSFNb anode- 2 is much smaller with significant and continuous activation. The detailed fitting results of $R_{H}$ and $R_{L}$ for the two LSFNb anodes are given in Table 1 for a better comparison.

TABLE I. Time dependence of the deconvoluted polarization resistance of LSFNb anode-1 and LSFNb anode- 2 .

\begin{tabular}{cccccc}
\hline Resistance $\left(\mathbf{\Omega} \cdot \mathbf{c m}^{2}\right)$ & $\mathbf{1} \mathbf{~ h}$ & $\mathbf{1 0 ~ h}$ & $\mathbf{5 0 ~ h}$ & $\mathbf{1 0 0} \mathbf{~}$ & $\mathbf{2 0 0} \mathbf{~ h}$ \\
\hline$R_{H}$ of LSFNb anode-1 & 0.16 & 0.14 & 0.12 & 0.09 & 0.09 \\
\hline$R_{L}$ of LSFNb anode-1 & 1.08 & 1.12 & 0.96 & 0.91 & 0.83 \\
\hline$R_{H}$ of LSFNb anode-2 & 0.09 & 0.08 & 0.06 & 0.05 & 0.03 \\
\hline$R_{L}$ of LSFNb anode-2 & 0.74 & 0.61 & 0.40 & 0.32 & 0.29 \\
\hline
\end{tabular}

Figure 2(a) and (b) compare the surface morphologies of LSFNb anode made from 7:2.5 and 7:4-slurries. Better microstructure with higher porosity and more homogeneous particles is obtained in LSFNb anode made from thin slurry, which is in consistent with the polarization resistance $\left(R_{P}\right)$ results of the two anodes, indicating that using thin slurry is an effective way to optimize the SOFCs and alleviate agglomeration. Meanwhile, some nanoparticles are exsolved on the surface of parent LSFNb anode particles after longterm operation as shown in Figure 2(c) and (d).
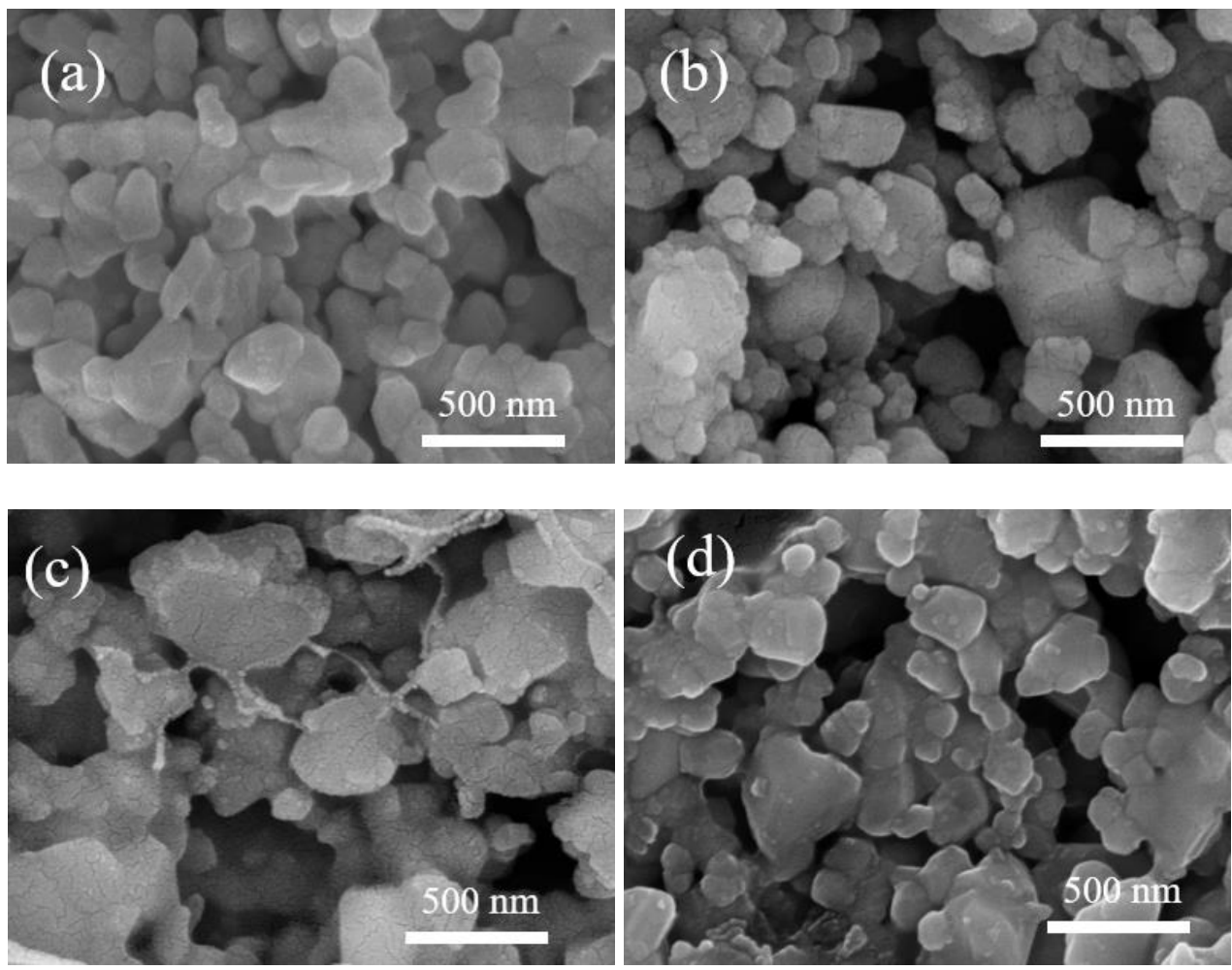

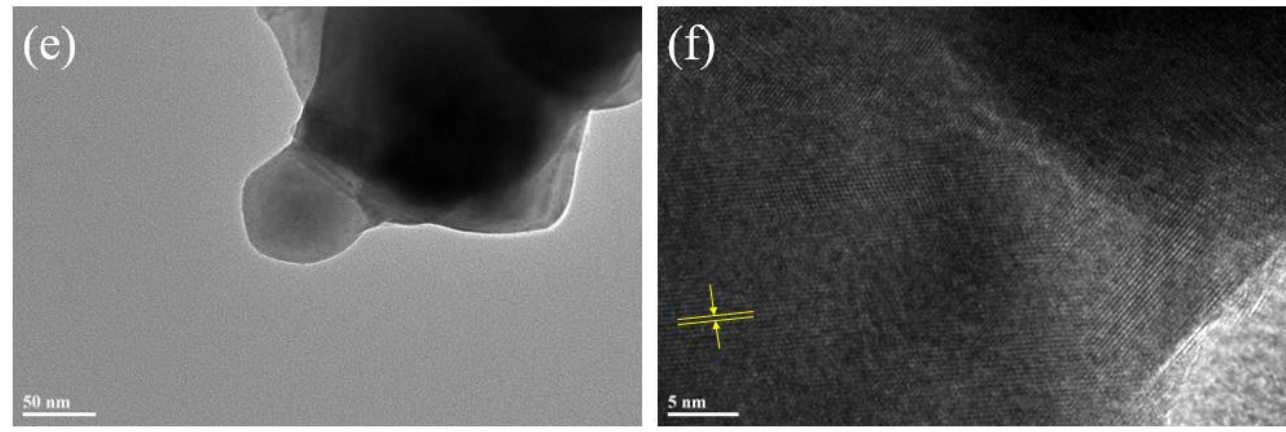

Figure 2. SEM images of LSFNb anode made from 7:2.5 slurries: (a) before test, (c) after the 200-h operation; SEM images of LSFNb anode made from 7:4 slurries: (b) before test, (d) after the 300-h operation. (e) Bright field-TEM image of reduced LSFNb. (f) High resolution-TEM image of the exsolved nanoparticle.

Reduced LSFNb powder for TEM measurement was prepared by annealing in wet hydrogen at $800{ }^{\circ} \mathrm{C}$ for $5 \mathrm{~h}$. As shown in Figure 2(e), there is a nanoparticle with the diameter of 50 nanometers precipitate from the parent particle with obvious boundary, indicative of separation between parent particle and the generated particle. HR-TEM image shown in Figure 2(f) shows that the distance between diffraction fringes of the exsolved nanoparticle is measured to be $0.352 \mathrm{~nm}$, which can be indexed with (012) crystal plane of $\mathrm{Fe}_{2} \mathrm{O}_{3}$. The exsolved $\mathrm{Fe}^{0}$ nanoparticles are easily oxidized when exposed to air, so the composition of the exsolved nanoparticles is reasonably $\mathrm{Fe}^{0}$ in reducing environment. Above all, surface morphologies of LSFNb anodes made from different slurries clearly reveal that LSFNb made from 7:4-slurry has better microstructure without obvious agglomeration during the long-term operation till $300 \mathrm{~h}$ with more amount of $\mathrm{Fe}^{0}$ nanoparticles exsolved on the surface.

Therefore, the continuous decrement of $R_{H}$ and $R_{L}$ for LSFNb anode- 2 might relate to such process: the doping of $\mathrm{Nb}$ on the B-site could promote the structural stability of LSF, but lead to the drop of oxygen vacancies at the same time (16). Consequently, the surface gas exchange ability of LSFNb would decrease since the large value of $R_{L}$ of LSFNb anode at the beginning shown in Figure 1. $\mathrm{Fe}^{0}$ metallic nanoparticles are exsolved from parent particles when the LSFNb anode exposed to reducing atmosphere along with the formation of more active oxygen vacancies. Oxygen vacancies are also benefit for gas adsorption and dissociation and the corresponding electrochemical performance of LSFNb anode. The anode gradually becomes a perovskite substrate with nano-sized metal particles in-situ exsolved during the operation of SOFC in $\mathrm{H}_{2}$. On the one hand, $\mathrm{Fe}^{0}$ metallic exsolutions could promote the charge transfer ability of LSFNb anode, causing the decrement of $R_{H}$. On the other hand, nano-sized $\mathrm{Fe}^{0}$ particles are active functional nanocatalysts, which can promote the adsorption and dissociation of gas. $\mathrm{Fe}^{0}$ nanoparticles are much more catalytic active compared with perovskite oxides, correspondingly fuels adsorption and dissociation processes are more easy to proceed, leading to the significant $R_{L}$ decrement of LSFNb anode- 2 during the long-term operation because more amount of oxygen vacancies and more $\mathrm{Fe}^{0}$ metallic exsolutions are generated $(20,23)$.

For simplicity, the single cells made from slurries with electrode/organic binder at the weight ratio of 7:2.5 and 7:4 were named as cell-1 and cell-2, respectively. After operated 
under constant current density of $0.3 \mathrm{~A} \cdot \mathrm{cm}^{-2}$ at $800^{\circ} \mathrm{C}$ for $1 \mathrm{~h}, 10 \mathrm{~h}, 50 \mathrm{~h}, 100 \mathrm{~h}$ and 200 h, $V$-I curves of cell-1 and cell-2 are shown in Figure 3(a) and (b), respectively. The maximum power density (MPD) of cell-1 increases with the operation time, from 244.8 $\mathrm{mW} \cdot \mathrm{cm}^{-2}$ at $1 \mathrm{~h}$ to the maximum value of $285.8 \mathrm{~mW} \cdot \mathrm{cm}^{-2}$ at $200 \mathrm{~h}$, which is associated with the activation of LSFNb anode and LSM/ScSZ cathode during the discharging process as we reported previously (20). The increment of MPD mainly occurs between 10 $\mathrm{h}$ to $100 \mathrm{~h}$, meanwhile a slight concentration polarization phenomenon begins to submerge at $10 \mathrm{~h}$, suggesting the difficulty of gas diffusion and adsorption increases. While the slight increment of MPD of cell-1 between $100 \mathrm{~h}$ and $200 \mathrm{~h}$ corresponds to the activation of electrodes, which is due to formation of more oxygen vacancies and $\mathrm{Fe}^{0}$ metallic nanoparticles in LSFNb anode and activation of LSM/ScSZ cathode during longterm operation at high temperatures.
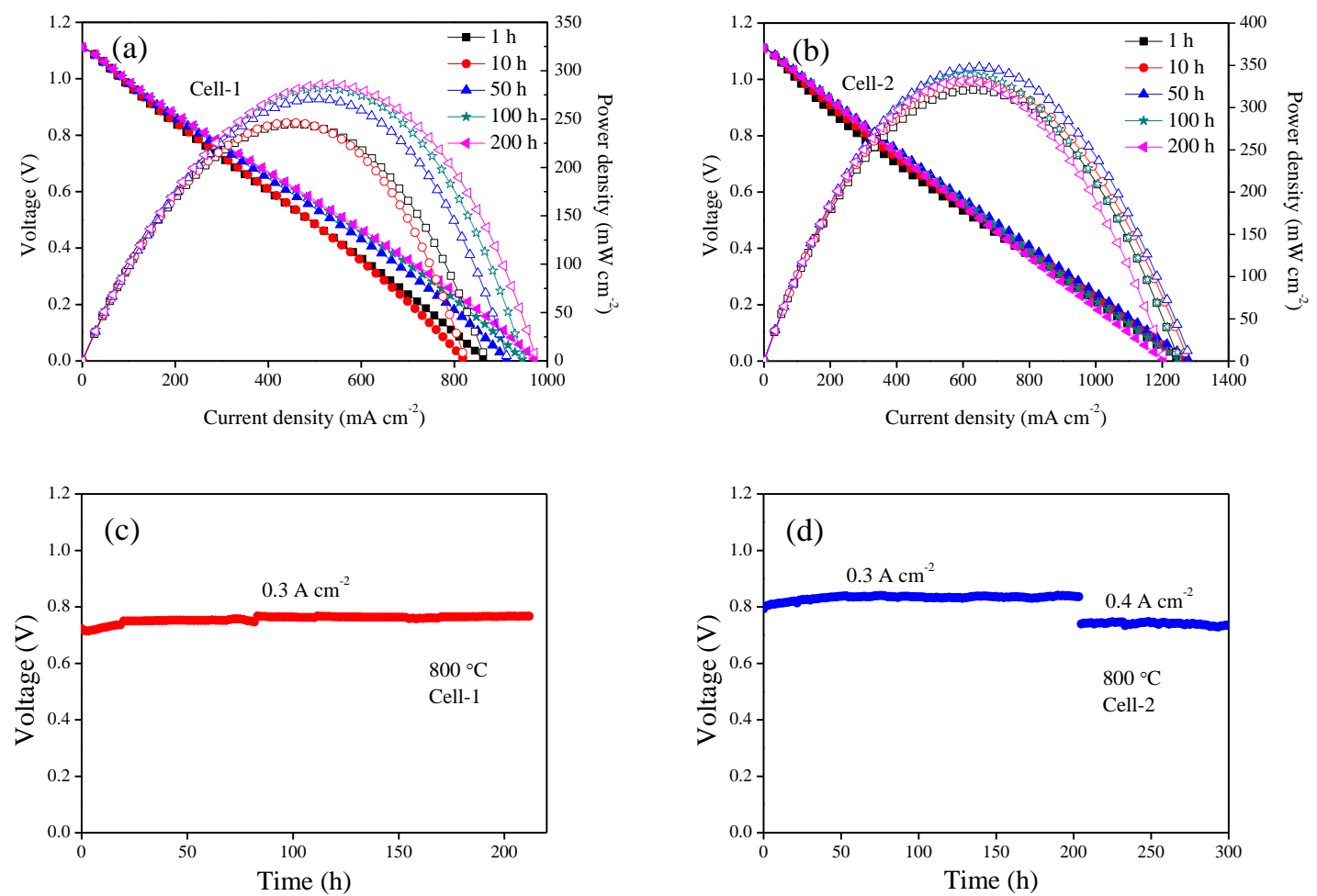

Figure 3. V-I polarization curves of cells made from slurries with different weight ratio of electrode/organic binder (a) 7:2.5 (Cell-1), (b) 7:4 (Cell-2); Long-term stability of cells (c) Cell-1, (d) Cell-2 at $800{ }^{\circ} \mathrm{C}$ using $\mathrm{H}_{2}$ as fuel.

Obviously, higher MPDs are obtained in cell-2 made from 7:4-slurries compared with those of the cell-1 as shown in Figure $3(\mathrm{~b})$, from $320.9 \mathrm{~mW} \cdot \mathrm{cm}^{-2}$ at $1 \mathrm{~h}$ to $331.9 \mathrm{~mW} \cdot \mathrm{cm}^{-}$ 2 at $200 \mathrm{~h}$, reaching the maximum value of $347.4 \mathrm{~mW} \cdot \mathrm{cm}^{-2}$ at $50 \mathrm{~h}$. No concentration polarization appears even at $200 \mathrm{~h}$, indicating the reasonable microstructures of anode and cathode made from 7:4-slurries with favorable thickness and sufficient porosity. The decrement of MPD of cell-2 after 50-h operation is probably due to the performance degradation of $\mathrm{ScSZ}$ electrolyte and LSM/ScSZ cathode made from 7:4-slurry, as the anode suffers a continuously activation process as shown in Table I.

Long-term stability of cell-1 and cell-2 were evaluated at $800{ }^{\circ} \mathrm{C}$ under a constant current density of $0.3 \mathrm{~A} \cdot \mathrm{cm}^{-2}$ for $200 \mathrm{~h}$. Stability of cell-2 was further investigated at a higher current density of $0.4 \mathrm{~A} \cdot \mathrm{cm}^{-2}$ after the 200 -h operation owing to its better output 
performance. The two cells exhibit excellent output stability with no degeneration of output voltage. The output voltage of cell-2 is slightly increased, from $0.79 \mathrm{~V}$ at the beginning and $0.84 \mathrm{~V}$ in the end under the current density of $0.3 \mathrm{~A} \cdot \mathrm{cm}^{-2}$ during the first $200 \mathrm{~h}$. The output voltage of cell-2 is almost unchanged during the following operation between $200 \mathrm{~h}$ and $300 \mathrm{~h}$ under the current density of $0.4 \mathrm{~A} \cdot \mathrm{cm}^{-2}$, varying from $0.735 \mathrm{~V}$ to $0.736 \mathrm{~V}$, showing the excellent stability at high current density during long-term operation. In conclusion, LSFNb anode with more reasonable microstructure exhibits better electrochemical performance and continuous activation and ability to alleviate agglomeration during long-term operation, which corresponds to formation of more oxygen vacancies and in-situ growth of nano-sized $\mathrm{Fe}^{0}$ metallic exsolutions in reducing atmosphere.

\section{Conclusions}

In this paper, evolution processes of $\mathrm{La}_{0.8} \mathrm{Sr}_{0.2} \mathrm{Fe}_{0.9} \mathrm{Nb}_{0.1} \mathrm{O}_{3-\delta}(\mathrm{LSFNb})$ anodes with diversity microstructures are evaluated. By adjusting the weight ratio of electrode and organic binder to 7:2.5 and 7:4 during preparation of slurries, different LSFNb anodes were obtained. AC impedance spectra clearly revealed that LSFNb anode made from 7:4slurry shows better microstructure and exhibits lower polarization resistance $\left(R_{P}\right)$ compared with those of LSFNb anode made from 7:2.5-slurry. Meanwhile, the agglomeration of LSFNb particles could be alleviated by using thin slurry, as the constant and significant decrement of $R_{L}$ for LSFNb anode made from thin slurry. Adopting thin slurry to prepare LSFNb anode with more porosity and more $\mathrm{Fe}^{0}$ metallic exsolutions is effective verified by SEM and TEM results. Better electrochemical performance was obtained in single cell made from 7:4-slurries, reaching up to $331.9 \mathrm{~mW} \cdot \mathrm{cm}^{-2}$ after operated for $200 \mathrm{~h}$, compared with $285.8 \mathrm{~mW} \cdot \mathrm{cm}^{-2}$ of whole cell made from 7:2.5slurries under the same testing condition. The two cells exhibit excellent stability as undetectable degeneration occurred during the whole stability test for over $200 \mathrm{~h}$. These results demonstrate that $\mathrm{LSFNb}$ made from thin slurry has better electrochemical performance, can also active continuously and alleviate agglomeration, making LSFNb a promising anode candidate with excellent catalytic activity and stability for solid oxide fuel cells.

\section{Acknowledgments}

This work was supported by the China Scholarship Council (CSC), National Natural Science Foundation of China $(51872067,21773048)$.

\section{References}

1. S. C. Singhal, Solid State Ionics, 135, 305 (2000).

2. W. Wang, C. Su, Y. Z. Wu, R. Ran and Z. P. Shao, Chem. Rev., 113, 8104 (2013).

3. R. M. Ormerod, Chem. Soc. Rev., 32, 17 (2003).

4. L. Yang, Y. M. Choi, W. T. Qin, H. Y. Chen, L. Blinn, M. F. Liu, P. Liu, J. M. Bai, T. A. Tyson and M. L. Liu, Nat. Commun, 2, 357 (2011). 
5. F. Wang, W. Wang, J. F. Qu, Y. J. Zhong, M. O. Tade and Z. P. Shao, Environ. Sci. Technol., 48, 12427 (2014).

6. M. Pihlatie, A. Kaiser and M. Mogensen, Solid State Ionics, 180, 1100 (2009).

7. S. W. Tao and J. T. S. Irvine, Nat. Mater., 2, 320 (2003).

8. X. Chen, S. L. Zhang, C. X. Li, G. J. Yang and C. J. Li, ECS Trans, 78, 1653 (2017).

9. Y. Zheng, C. Zhang, R. Ran, R. Cai, Z. Shao and D. Farrusseing, Adv. Mater., 57, 1165 (2009).

10. Y. H. Huang, R. I. Dass, J. C. Denyszyn and J. B. Goodenough, J. Electrochem. Soc., 153, A1266 (2006).

11. Q. Liu, X. Dong, G. Xiao, F. Zhao and F. Chen, Adv. Mater., 22, 5478 (2010).

12. S. Sengodan, S. Choi, A. Jun, T. H. Shin, Y. Ju, H. Y. Jeong, J. Shin, J. T. S. Irvine and G. Kim, Nat. Mater., 14, 205 (2015).

13. S. P. Simner, J. R. Bonnett, N. L. Canfield, K. D. Meinhardt, J. P. Shelton, V. L. Sprenkle and J. W. Stevenson, J. Power Sources, 113, 1 (2003).

14. Z. Lei, Q. S. Zhu and L. Zhao, J. Power Sources, 161, 1169 (2006).

15. B. A. Boukamp, Nat. Mater., 2, 294 (2003).

16. P. Shen, X. Liu, H. Wang and W. Ding, J. Phys. Chem. C, 114, 22338 (2010).

17. Z. Zhang, N. Xu, M. Han and F. Chen, Int. J. Hydrogen Energy, 39, 7402 (2014).

18. X. Wu, X. Zhou, Y. Tian, X. Kong, J. Zhang, W. Zuo and X. Ye, Electrochimica Acta, 208, 164 (2016).

19. C. Yang, Z. Yang, C. Jin, G. Xiao, F. Chen and M. Han, Adv. Mater., 24, 1439 (2012).

20. J. Li, B. Wei, Z. Cao, X. Yue, Y. Zhang and Z. Lü. ChemSusChem, 11, 254 (2018).

21. S. P. Jiang, J. P. Zhang and K. Foger, J. Electrochem. Soc., 147, 3195 (2000).

22. K. Chen and S. P. Jiang, Int. J. Hydrogen Energy, 36, 10541 (2011).

23. J. Li, B. Wei, X. Yue and Z. Lü. ChemSusChem, 11, 2593 (2018). 